\title{
Analysing Debris-Flow Impact Models, Based on a Small Scale Modelling Approach
}

\author{
Christian Scheidl • Michael Chiari • Roland Kaitna • Matthias Müllegger • \\ Alexander Krawtschuk • Thomas Zimmermann • Dirk Proske
}

Received: 8 December 2011/Accepted: 27 June 2012/Published online: 18 July 2012

(C) The Author(s) 2012. This article is published with open access at Springerlink.com

\begin{abstract}
The objective of this study is to analyse adaptable debris-flow impact models, which are very important for mitigation measurements and buildings using their sphere of influence. For this reason, 16 debris-flow experiments, on a small-scale modelling approach, were performed. Impact forces were measured with a force plate panel, consisting of 24 aluminium devices, coaxially mounted with resistance strain gauges. Flow velocities, flow heights as well as horizontal impact forces were sampled with a frequency of $2.4 \mathrm{kHz}$. Sub datasets of sampled raw force data were defined by applying an average median filter, a lowpass filter routine. Further, estimated peak pressure values as well as empirical coefficients of hydraulic impact models were compared, and the influence of signal processing is discussed.
\end{abstract}

Keywords Debris flow $\cdot$ Impact force $\cdot$ Physical modelling $\cdot$ Signal processing

\section{Introduction}

Debris flows endanger human living in mountainous regions all over the world. The design of structural mitigation measures, like debris-flow barriers, or the maintenance of infrastructures such as bridges, requires the estimation of potential impact forces caused by debris flows. Currently, no entirely mechanistically and theoretically based impact model is sufficiently accurate and computable in periods common for design offices (Proske et al. 2008; Hübl et al. 2009). Debris-flow impact models for engineering purposes are, therefore, mainly based on rational arguments and empirical approaches, as stated for instance by Egli (2005) or the Austrian code series ONR2480X; the latter is currently under

C. Scheidl $(\bowtie) \cdot$ M. Chiari · R. Kaitna · M. Müllegger · D. Proske Institute of Mountain Risk Engineering, University of Natural Resources and Life Sciences, Vienna, Peter-Jordan-Strasse 82, 1190 Wien, Austria

e-mail: christian.scheidl@boku.ac.at

A. Krawtschuk - T. Zimmermann

Institute of Structural Engineering, University of Natural Resources and Life Sciences, Vienna, Wien, Austria 
development. Wendeler (2008) analysed existing debris-flow impact models and their adaptability to design flexible debris-flow barriers.

Impact forces caused by real-scale debris-flow events have been measured at Mt. Yakedake in Japan (Okuda et al. 1977), in the Jiangjia Ravine in China (Zhang 1993; Hu et al. 2011), at the Schesatobel in Austria (König 2006) and in the Illgraben torrent in Switzerland (Wendeler et al. 2007). An example of a large scale experiment is given by DeNatale et al. (1999) and Bugnion et al. (2011). The advantage of large scale debris-flow experiments or impact force measurements of natural debris flows at monitoring stations is that scaling considerations with regard to the process are not necessary. However, the possibility to gather systematic data for controlled boundary conditions is limited. For instance, the unknown frequency of occurrence of a debris-flow event and therewith the effort of the installation and operation of measurement devices are main disadvantages of real-scale observations. And for large scale experiments, the expected volume of the event makes the design of the measurement setup cost-intensive and flow and material parameters are often unknown.

For this reasons, laboratory small scale experiments (measuring debris-flow impacts) have also been carried out, accepting the difficulty in scaling debris flows for physical modelling (Armanini and Scotton 1992; Ishikawa et al. 2008; Hübl and Holzinger 2003; Tiberghien et al. 2007; Monney et al. 2007; Shieh et al. 2008; Wendeler 2008). Due to the complex flow behaviour of debris flows including scale dependent interactions between the solid and the fluid phase (Iverson and Denlinger 2001; Iverson et al. 2011), a common approach to extrapolate from experimental scale to field scale is often based on hydrodynamic approaches, assuming geometric as well as simple kinematic similarity. This seems to be justified, since these experiments focus on the impacts of sediment-fluid mixtures on an obstacle rather than on the flow dynamics of debris flows. Kinematic similarity is characterised by the dimensionless Froude number $\left(F_{r}\right)$, which is the ratio of inertial and gravitational forces of the flowing mass. For this approach, the Froude number should have values similar to natural debris-flow events. Hübl et al. (2009) showed that the impact forces of the real-scale observations have mainly been estimated in a Froude range between 0 and 2, but only the tests by Tiberghien et al. (2007) reach this range. Miniaturised tests were mainly carried out at higher Froude numbers, concluding that models based on these experimental data do not comply with field data

The objective of this study is to analyse impact forces of granular and viscous debris flows based on small scale laboratory experiments. All tests rely on Froude scaling, accomplished with Froude numbers, $F_{r}<3$. After an overview of existing debris-flow impact models, a detailed description of the laboratory flume as well as the experimental setup is given. Measured peak flow heights, maximum velocities, and peak pressure values are presented. The measurements are compared to existing impact models, especially to the modified hydrodynamic model of Hübl and Holzinger (2003), which is strongly related to the Austrian code series ONR2480X currently under development. Finally, observations of single, short time impacts of large particles, significantly exceeding the peak pressure values, are discussed.

\section{Debris-Flow Impact Models}

Debris-flow impact models suggested for the design of engineering structures can be classified into hydraulic and solid-collision models (Hübl et al. 2009). This twofold classification reflects the complexity of debris-flow processes, where the impact can either be caused by fluid-phase slurry thrusting or a point-wise loading due to coarse solid 
particle collision (Hu et al. 2011). These solid body impact models assume elastic material behaviour and are mainly based on the Hertz model. Alternative models, considering viscous-elastic and elastic-plastic behaviour, are proposed by Walton and Braun (1986) and Thornton (1997). This study focuses on hydraulic models, which can be separated into hydrostatic and hydrodynamic models.

The hydrostatic models by Lichtenhahn (1973) and Armanini (1997) are useful because only the debris-flow height is required and because often the height of the structures is taken as debris-flow height for checking dam design purposes. In general, the hydrostatic formula can be written as:

$$
p_{\text {peak }}=k \rho g h
$$

Here, $p_{\text {peak }}$ denotes the maximum debris-flow impact pressure with the parameter $k$ as an empirical factor. The characteristic of the debris-flow process is described by its bulk density $\rho$ and the total flow height $h$. The acceleration due to gravity is given by $g$. The maximum impact pressure $p_{\text {peak }}$ is not related to statistical considerations, but to the maximum pressure value in the load distribution on the structure (Hübl et al. 2009). Lichtenhahn (1973) proposed $k$-values between 2.8 and 4.4. A maximum static debrisflow impact pressure, exceeding roughly 5 times the hydrostatic pressure, was given by Armanini (1997). Based on small-scale debris-flow model tests, Scotton and Deganutti (1997) measured the impact on a vertical obstacle. They report $k$-values between 2.5 and 7.5, depending on the viscosities of the interstitial fluids and the hydraulic conductivity.

The hydrodynamic formulas have the form

$$
p_{\text {peak }}=a \rho v^{2}
$$

with the empirical factor $a$ and the debris-flow velocity $v$. The empirical factor value $a$ depends on the flow type. For example, for laminar flow and fine grained material, Watanabe and Ike (1981) estimate $a=2.0$. For coarse material, values up to $a=4.0$ are given by Egli (2005). Zhang (1993) recommends values of $a$ between 3.0 and 5.0, based on field measurements of over 70 debris flows. Based on laboratory impact measurements on flexible debris-flow barriers, Wendeler (2008) lists up scaled field values of $a$ between 0.7 and 2.0. Bugnion et al. (2011) proposed $a$ values ranging between 0.4 and 0.8 , with a maximum of 2.0 after analysing real-scale experiments of hill slope debris-flow impact measurements on small obstacles. The values denoted by Bugnion et al. (2011) may be biased by the damping effect of an elastomer layer as a overload protection within their load cells.

A modified hydrodynamic formula is given by Hübl and Holzinger (2003). They measured impact forces on debris-flow barriers, based on miniaturised tests. To achieve a scale-free relationship, they further relate the Froude number $\left(F_{r}\right)$ to normalised impact forces. Based on a correlation analysis, a numerical expression is given as:

$$
p_{\text {peak }}=5 \rho v^{0.8}(g h)^{0.6}
$$

Combined models considering hydrostatic and hydrodynamic elements have been suggested by Kherkheulidze (1969) and Arattano and Franzi (2003).

A comparison of selected hydraulic impact models was proposed by Hübl et al. (2009) using the Bernoulli energy concept to transfer hydrodynamic models into hydrostatic models: 
Table 1 Comparison of different $k$ factors for selected impact models, modified after (Hübl et al. 2009)

\begin{tabular}{llll}
\hline Hydraulic model & Study & $k[-]$ & Notes \\
\hline Static & Lichtenhahn (1973) & $2.8-4.4$ & Transferred from water density \\
Static & Armanini (1997) & 5.0 & - \\
Static & Scotton and Deganutti & $2.5-7.5$ & Miniaturised tests \\
& $(1997)$ & & \\
Dynamic & VanDine (1996) & $1.5 A$ & Introduction of an area $A$ \\
$\begin{array}{l}\text { Dynamic } \\
\text { Dynamic }\end{array}$ & Watanabe and Ike (1981) & 4.0 & - \\
$\begin{array}{l}\text { Dynamic } \\
\text { Dynamic }\end{array}$ & Tiberghien et al. (2007) & 13.5 & $\begin{array}{l}\text { Miniaturised tests } \\
\text { Wendeler (2008) }\end{array}$ \\
$\begin{array}{l}\text { Dynamic } \\
\text { Bugnion et al. (2011) }\end{array}$ & $1.4-4.0$ & $\begin{array}{l}\text { Miniaturised tests on flexible } \\
\text { barriers }\end{array}$ \\
$\begin{array}{l}\text { Modified dynamic } \\
\text { Mixed, static and } \\
\text { dynamic }\end{array}$ & Hübl and Holzinger (2003) & 7.5 & $\begin{array}{c}\text { Real-scale experiments on hill slope } \\
\text { Kebris flows }\end{array}$ \\
\hline
\end{tabular}

$$
k \rho g h=a \rho \frac{v^{2}}{2}
$$

In Table 1, we compare the back calculated static impact factor $k$ for selected studies, using Eq. (4) and assuming $F_{r}=1$. Although Table 1 shows a high variance of the normalised $k$-values, their range is within the order of magnitude as proposed by the field analysis of Zhang (1993).

\section{Methods}

\subsection{Scaling Considerations}

The derivation in scaling findings from the laboratory tests to prototype conditions is assumed on geometric, kinematic and dynamic similarity. The characteristic length scale (geometric similarity), defined for the experiments of this study $\left(\lambda^{\prime}\right)$, is given by the ratio of the prototype $-\left(l^{*}\right)$ and laboratory - $(l)$ conditions:

$$
\lambda^{\prime}=\frac{l^{*}}{l}=20
$$

The limits of scaling considerations are mainly caused by performing dynamic similarity, sufficient to draw rudimentary conclusions about momentum transport and the attendant state of stress in the mixture (Iverson 1997). Full dynamic similarity of all forces, acting in nature and the model, is not feasible by using the same fluid with the same viscosity. Therefore, dimensional analysis of debris flows considers the fluid-slurry dynamic viscosity among other variables, significant to the debris-flow phenomenon (Davies 1994; Iverson 1997). However, data on viscosities of debris-flow events vary substantially in nature. Cui et al. (2005) measured viscosities ranging from 0.4 to $15 \mathrm{~Pa}$.s, based on samples of fine grained debris-flow events occurring in the Jiangia Ravine in China. Tecca et al. (2003) derived Bingham parameters, back calculated from observation and deposits 
Table 2 Range of laboratory and prototype parameters for the experiments of this study

\begin{tabular}{lllllll}
\hline & $B[\mathrm{~m}]$ & $d_{\max }[\mathrm{m}]$ & $v[\mathrm{~m} / \mathrm{s}]$ & $h[\mathrm{~m}]$ & $F_{r}[-]$ & $p_{\text {peak }}\left[\mathrm{kN} / \mathrm{m}^{2}\right]$ \\
\hline laboratory & 0.45 & 0.05 & $0.6-2.5$ & $0.06-0.16$ & $0.7-3.2$ & $0.28-1.02$ \\
prototype & 9.00 & 1.00 & $2.8-10.9$ & $1.20-3.20$ & $0.7-3.2$ & $5.66-20.31$ \\
\hline
\end{tabular}

Here, $B$ denotes the flow width, whereas $d_{\max }$ refers to the maximum grain size. The maximum measured velocities and flow heights are denoted, respectively, by $v$ and $h . F_{r}$ refers to the related Froude number and $p_{\text {peak }}$ refers to the maximum debris-flow impact pressures (Eq. 1-3)

of granular debris-flow events. They report viscosities ranging from 5 to $75 \mathrm{~Pa}$.s, varying by a factor of five compared to the measurements of the muddy debris flows of the Jiangia Ravine. We, therefore, defined two different bulk mixtures for our experimental tests, reflecting a more granular or viscous flow behaviour. Since viscosities of debris-flow events have yet to be verified, we further decided to apply the Froude scaling concept to our experimental test:

$$
\frac{v^{*}}{\sqrt{g l^{*}}}=F_{r}=\frac{v}{\sqrt{g l}}
$$

Here, $v^{*}$ and $v$ refer, respectively, to the prototype and laboratory maximum surface velocities at the debris-flow front. The gravitational attraction is denoted by $g$, whereas $l^{*}$ as well as $l$ denote the peak flow heights of the prototype and laboratory experiments, respectively.

The prototype pressure values $\left(p^{*}\right)$ are then estimated, based on the measured pressure values $(p)$ by means of:

$$
p^{*}=p \lambda^{\prime}
$$

In Table 2, selected laboratory and prototype parameters for this study, satisfying Froude scaling and based on the characteristic length scale (Eq. 5), are compared.

\subsection{Debris-Flow Material}

The experimental bulk mixtures are based on water combined with a defined grain-size distribution of solid particles, which may consist of loam $(0.0002-0.1 \mathrm{~mm})$ and bedload sediments $(0.1-50 \mathrm{~mm})$. The dry mass of the particles was kept constant with $370 \mathrm{~kg}$, and only the water content remained variable. The maximum used grain diameter of $50 \mathrm{~mm}$ was defined in accordance to the maximum flow width of the flume $(450 \mathrm{~mm})$, as well as to the size of the impact area of each aluminium device $(40 \times 40 \mathrm{~mm})$ within the force plate. The total bulk density $\left(\rho_{d f}\right)$ was averaged to be $2,000 \mathrm{~kg} / \mathrm{m}^{3}$. Figure 1 shows the grain-size distribution used for this study compared to selected grain-size distributions for debris flows based on field observations (VAW 1992; Hu et al. 2011). The grain-size distribution, used by D'Agostino et al. (2010), refers to debris-flow material used in their laboratory tests. The granular bulk mixture consisted only of particles with diameters larger than $0.1 \mathrm{~mm}$. Here, we substituted the finer particles with water to achieve a constant mass concentration.

The viscous mixture included fine particles consisting of $26 \%$ clay, $60 \%$ silt and $14 \%$ sand. The results of a mineral analysis showed $15 \%$ of swellable Smektit within the clay fraction, which counteracts phase seperation for a longer time period. 


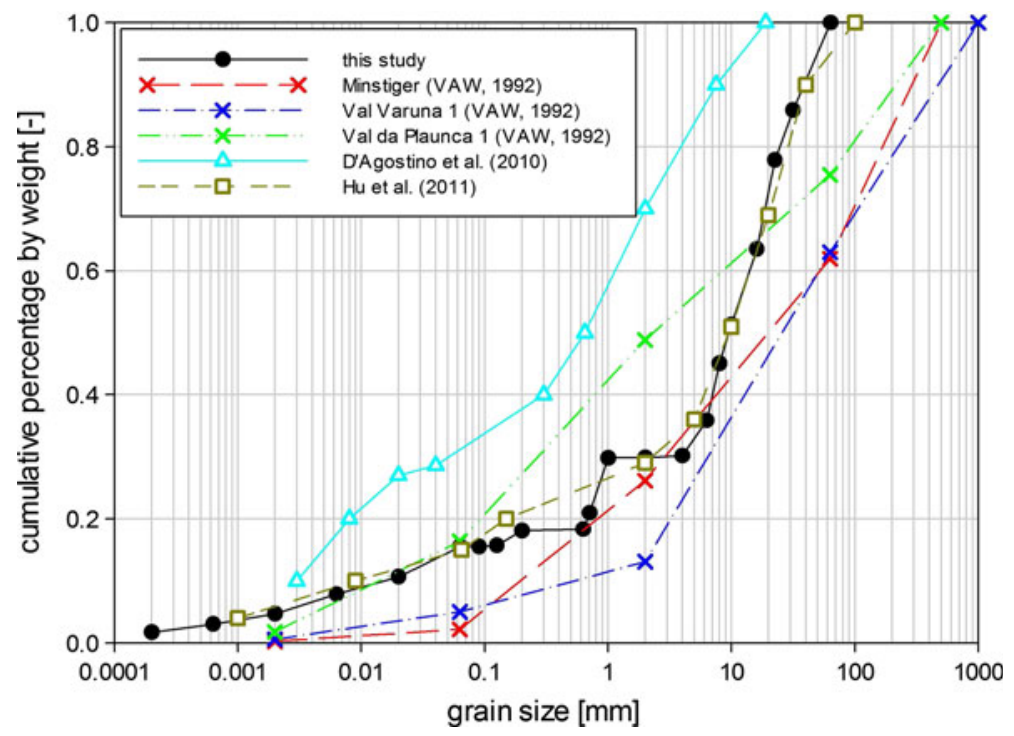

Fig. 1 Grain-size distribution of the debris-flow material used in this study, compared to selected grain-size distributions of observed events in Switzerland (VAW 1992), China (Hu et al. 2011) and used for laboratory tests by D'Agostino et al. (2010)

\subsection{Experimental Device}

The experiments were conducted at the Institute of Mountain Risk Engineering (IAN) at the University of Natural Resources and Life Sciences, Vienna. The flume is made out of wood and has a total length of $6.5 \mathrm{~m}$. For this study, the slope of the flume remained fixed at $30 \%$ and had a constant flow width of $0.45 \mathrm{~m}$ (Fig. 2). Functionally, the construction can be separated into a start (reservoir) and a measuring section (flume).

The start section is about $2 \times 1 \mathrm{~m}$ in plan view and can hold a total volume of $0.33 \mathrm{~m}^{3}$, which can be released with a simple start mechanism, imitating a dam-break scenario. Figure $3 \mathrm{a}$ shows the start section with the starting mechanism at the moment of the release of a viscous debris-flow experiment.The measuring section begins after the start section and has in total a length of $4.5 \mathrm{~m}$. The height of the side walls amounts to $0.5 \mathrm{~m}$. Since the flume slope remained constant, the roughness of the basal layer of the measuring section was adapted to meet the desired Froude numbers. After several tests, an epoxy-sand coating with a $d_{50}$ of about $1 \mathrm{~mm}$ showed most suitable results.

The measuring devices are mounted along the measuring section and are comprised of three ultrasonic devices, installed to measure flow heights at fixed lengths from the starting mechanism (Fig. 3b) and one force plate panel, installed at the end of the flume, to measure horizontal impact forces.

This force plate panel consists of 24 cuboidal aluminium devices, coaxially mounted with resistance strain gauges (Fig. 4a). The impact area of each load cell has a quadratic shape of $0.04 \times 0.04 \mathrm{~m}$, which results in a total impact area of the force plate panel of $0.0384 \mathrm{~m}^{2}$. In Fig. $4 \mathrm{~b}$, the frontal view (impact side) of the force panel, discretised due to 24 load cells, can be seen. Each load cell was individually calibrated in steps of $1 \mathrm{kN}$ over a range of 0 to $4 \mathrm{kN}$. The calibration was done by using a universal testing machine (Fig. 4d). Size and situation of the load cells within the force plate is shown in Fig. 5.The 


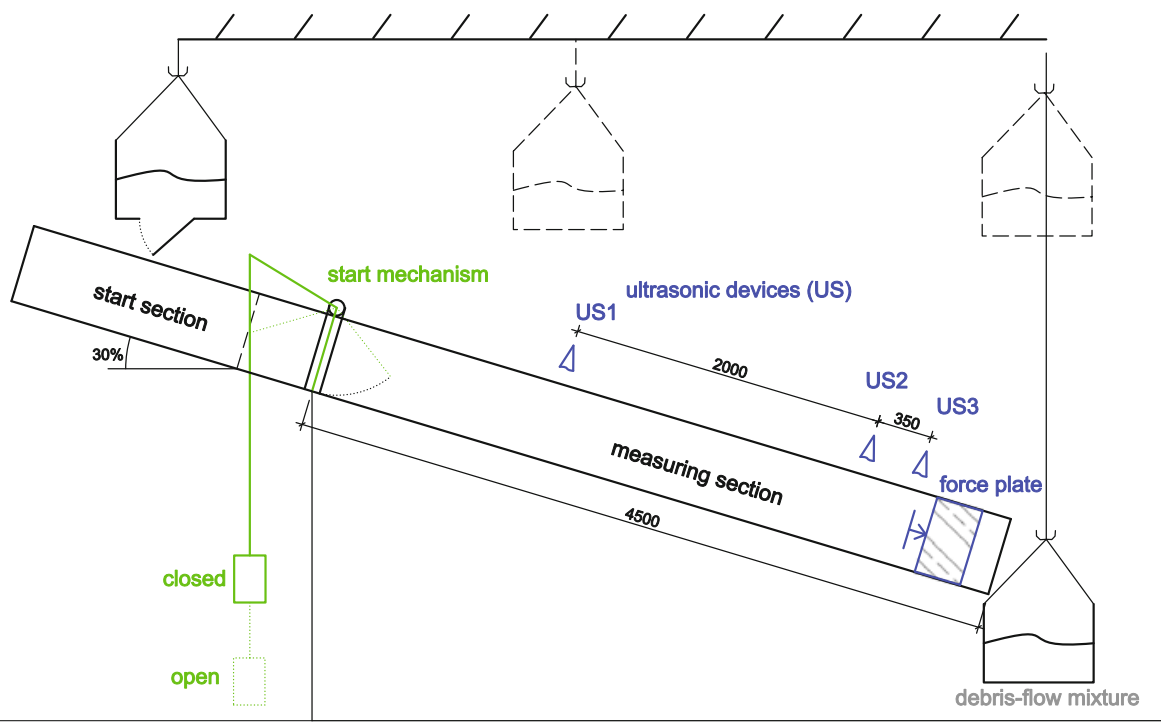

Fig. 2 Sketch of the experimental flume at the IAN-laboratory. All specifications are in mm
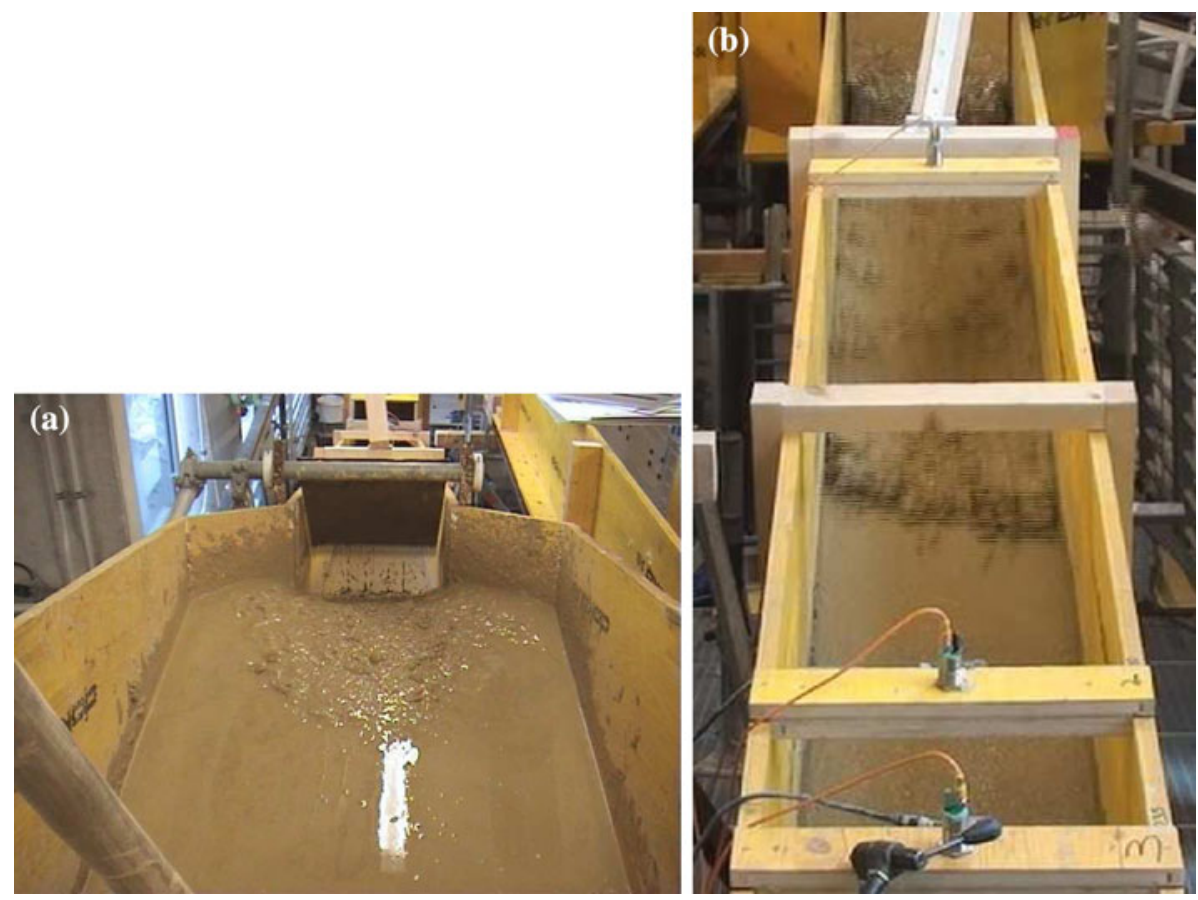

Fig. 3 a Start section and starting mechanism (steel plate) at the moment of a debris-flow release from top view. b Bottom view measuring section with the three ultrasonic devices US1, US2 and US3 (counting from upstream), mounted in the middle of the channel 

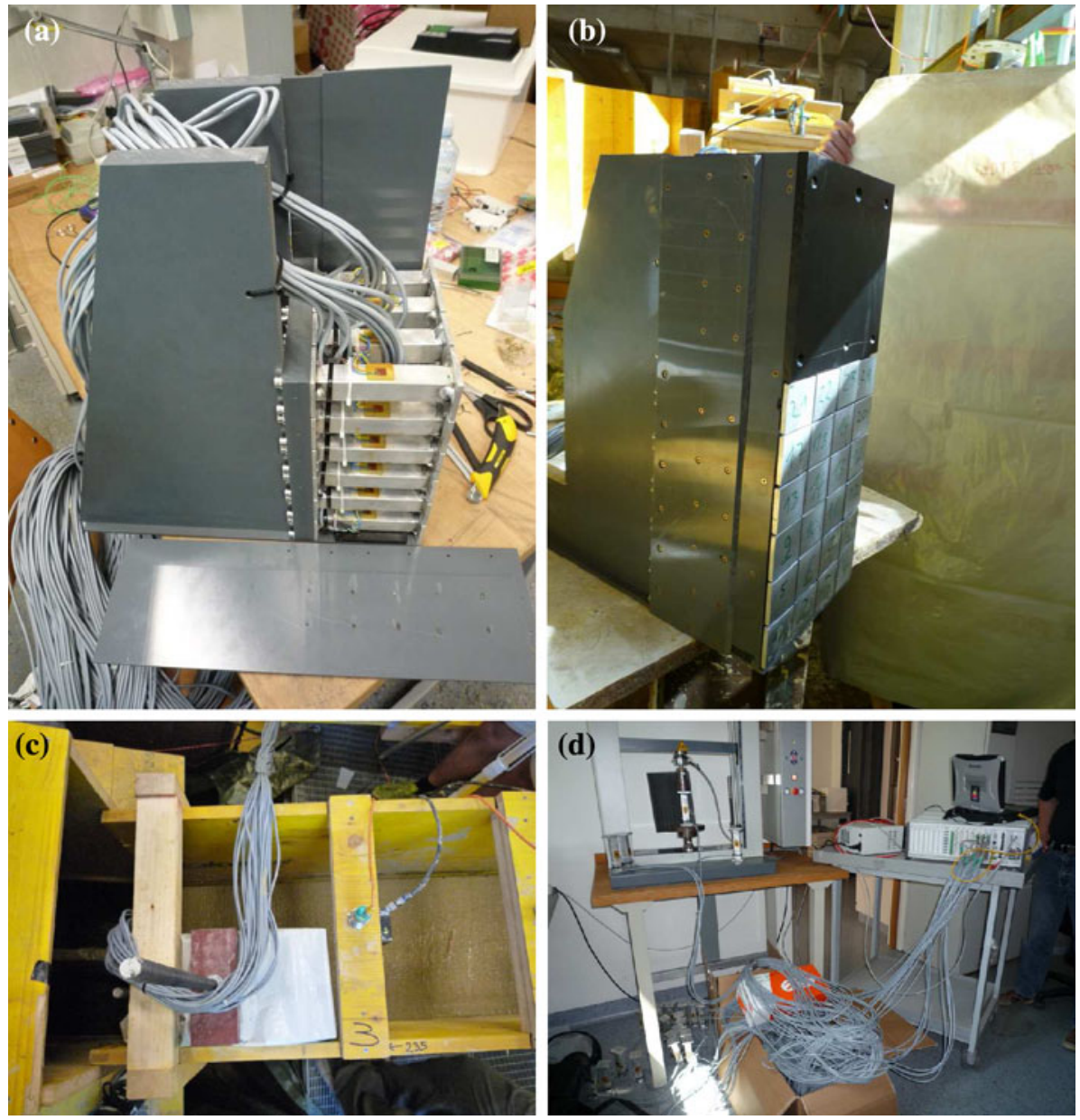

Fig. 4 a Detailed view of the cuboidal aluminium devices to measure horizontal load forces based on resistance strain gauges. b Frontal view of the force plate panel, discretised due to 24 load cells. c Plan view of the installed force plate panel, related to the flume construction. d Universal testing machine to calibrate the load cells individually

design of the force plate allows an installation on the orographic left side, or in the centre of the flume, so that the flow was never completely stopped by the force plate. Additionally, three camera devices were installed, showing videos with a view from the starting box, the force plate and the measuring section.

In total, 30 experiments were carried out, whereas the number of experiments was limited due to the large amount of the total mass $(\approx 400 \mathrm{~kg})$, which had to be mobilised. Each experiment consisted of $370 \mathrm{~kg}$ solid particles, based on the defined grain-size distribution (Fig. 1), and combined with a certain amount of water. The slope of the flume as well as the basal friction condition remained fixed for all experiments. The variability of the flow dynamics of each experiment was therefore only controlled by the variability of the added water content by weight. Thus, a low water content of the bulk mass resulted in low Froude numbers. Minimum water contents per weight and Froude numbers were observed for experiments with flow heights approximating to the maximum grain size of 
Fig. 5 Size and situation of the load cells forming the force plate. Each square represents one load cell, starting with load cell $\mathrm{Nr}$. 1 in the lower left corner to load cell Nr. 24 in the upper right corner

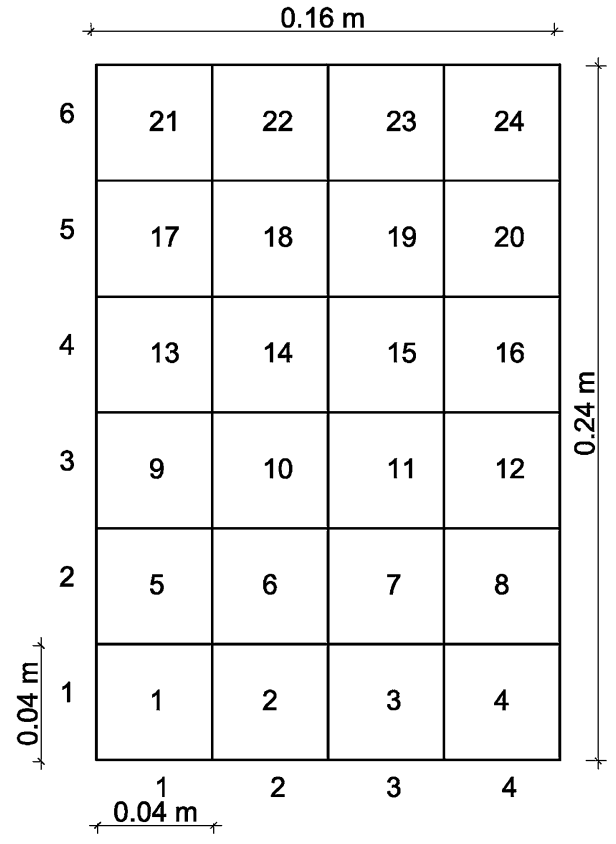

the solid particles $(0.05 \mathrm{~m})$. With increasing water content, we further observed an increase in the turbulence of the bulk mixture and a decoupling of material and fluid. Therefore, experiments of $F_{r}>3$ were excluded from further analysis. Table 3 gives an overview of the selected experiments, the added water contents per weight and the estimated maximum flow parameters. The variance of the measured maximum flow velocities and flow heights, and Froude numbers, for identical experimental setups, are in a small range. However, the deviation of the measured maximum velocities for each setup might be explained due the relatively short measuring sector, which affects the development of a full steady flow.

For each experiment, the impact forces of all load cells and the flow heights along the flume were sampled over a certain time period. This time period varied for each experiment since the opening of the starting mechanism and the start of the measuring devices were not coincidental.

All measured data were sampled with a frequency of $2.4 \mathrm{kHz}$ using a MGCplus datalogger of the company HBM. The results were stored in ascii-file format.

\subsection{Processing of the Impact Signal}

Measurement of single impacts of short duration needs a sampling frequency sufficient to capture the true peak force. In this study, we do not focus on these single impacts of very short duration, but on the maximum bulk impact force over durations relevant for engineering design purposes. However, since there is no critical duration of impacts on an engineering structure, our data analysis compares different approaches.

For each experiment, 24 time series of force signals (based on the 24 load cells) were sampled. All the scanned raw data were primarily filtered, regarding the Nyquist-Shannon sampling theorem: 
Table 3 Overview of the selected experiments, used for further analyses

\begin{tabular}{llllll}
\hline Nr. & Bulk mixture setup & $v_{\max }[\mathrm{m} / \mathrm{s}]$ & $h_{\text {peak }}[\mathrm{m}]$ & $F_{r}[-]$ & $W[\%]$ \\
\hline 1 & Viscous & 1.355 & 0.140 & 1.16 & 0.18 \\
2 & Viscous & 0.931 & 0.080 & 1.05 & 0.16 \\
3 & Viscous & 1.159 & 0.120 & 1.07 & 0.16 \\
4 & Viscous & 1.277 & 0.070 & 1.54 & 0.16 \\
& Mean value & 1.180 & 0.103 & 1.20 & \\
& Standard deviation & 0.185 & 0.033 & 0.23 & \\
5 & Granular & 1.767 & 0.160 & 0.61 & 0.16 \\
6 & Granular & 0.942 & 0.155 & 0.76 & 0.16 \\
7 & Granular & 0.959 & 0.150 & 0.80 & 0.16 \\
8 & Granular & 1.032 & 0.140 & 0.88 & 0.16 \\
9 & Granular & 0.725 & 0.110 & 0.70 & 0.16 \\
10 & Granular & 0.634 & 0.130 & 0.56 & 0.16 \\
& Mean value & 0.843 & 0.140 & 0.72 & \\
& Standard deviation & 0.156 & 0.018 & 0.12 & \\
11 & Granular & 1.469 & 0.125 & 1.33 & 0.27 \\
12 & Granular & 2.147 & 0.070 & 2.59 & 0.27 \\
13 & Granular & 2.455 & 0.060 & 3.20 & 0.27 \\
14 & Granular & 1.480 & 0.095 & 1.53 & 0.27 \\
15 & Granular & 2.132 & 0.080 & 2.41 & 0.27 \\
16 & Granular & 1.800 & 0.105 & 1.77 & 0.27 \\
& Mean value & 1.977 & 0.089 & 2.20 & \\
& Standard deviation & 0.342 & 0.024 & 0.67 & \\
\hline
\end{tabular}

The maximum measured velocities and flowheights are respectively denoted by $v_{\max }$ and $h_{\text {peak }} . F_{r}$ refers to the related Froude number and $W$ denotes the water content in percent per weight

$$
f_{\text {scan }}>2 f_{\max }
$$

Considering the applied scan frequency $\left(f_{\text {scan }}\right)$, Eq. 8 yields a refined dataset with a maximum frequency $\left(f_{\max }\right)$ for data interpretation. Hence, the force signals, used for further analysis, consist of sampled data within a frequency range between 0 and 1,190 Hz. This dataset is referred to as the dataset of the entire signals (dataset $A$ ). Figure 6 shows forces over time, based on dataset $A$ of load cell 1 and experiment 1 . Also shown is the median of the entire signals based on a running window of $300 \mathrm{~Hz}$, which is denoted as the dataset of the average signals (dataset $B$ ). The window size was chosen as a best-fit parameter to eliminate random effects but keeping the long-term response of the signal. Random effects seemed to be based on the resonance frequency of the force plate and on single impacts of very short duration. Certainly, dataset $B$ also reduces the peak values of the force signals. However, analysis showed that the random effects were measured in higher frequency ranges. Dataset $C$ is therefore defined as a low-pass filtered version of dataset $A$. The related threshold frequency (maximum low pass frequency) is based on the following theoretical considerations. Video observations showed that the total area of load cells, which measured maximum forces over time, were always entirely hit by the experimental debris-flow front. Assuming an experimental "debris" flow as a mono-phase flux, we defined the maximum low pass frequency $f_{\max _{1}}$ based on the average maximum front 


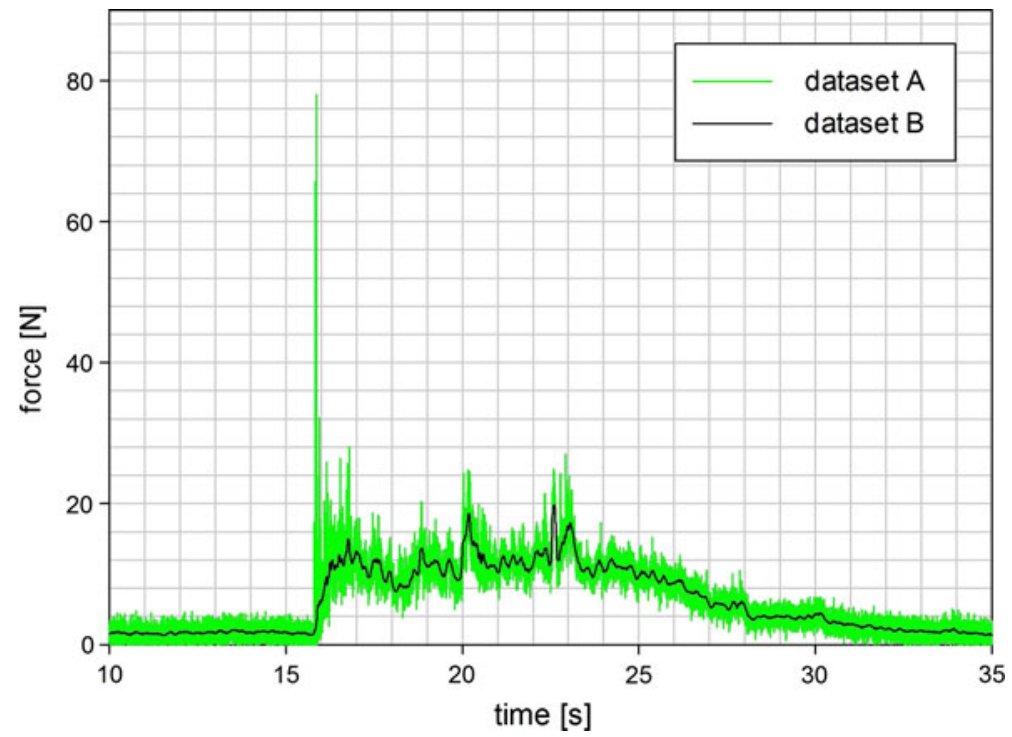

Fig. 6 Entire dataset $(A)$ as well as averaged dataset $(B)$ of experiment $\mathrm{Nr} .1$ measured with load cell $\mathrm{Nr} .1$

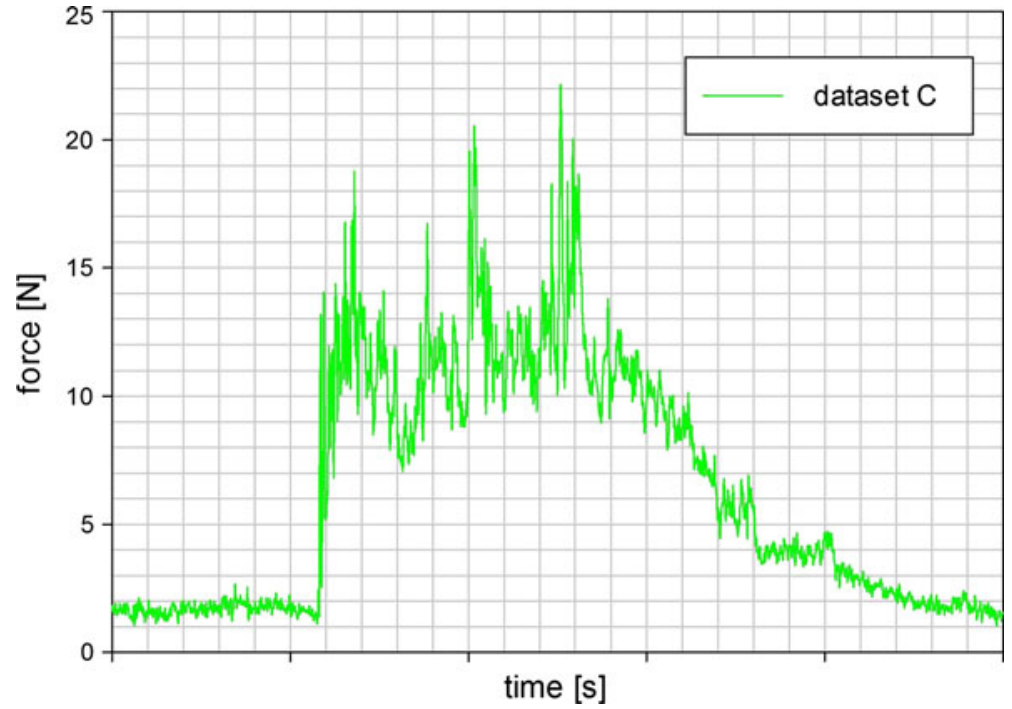

Fig. 7 Low pass filtered dataset $(C)$ of experiment Nr. 1 measured with load cell Nr. 1

velocity of $v_{a v}=1.3 \mathrm{~m} / \mathrm{s}$ and the maximum grain diameter $\left(d_{\max }=0.05 \mathrm{~m}\right)$, which is approximately the same as the total height of a load cell.

$$
f_{\max _{1}}>\frac{v_{a v}}{d_{\max }}=\frac{1.3}{0.05}=26 \mathrm{~Hz}
$$




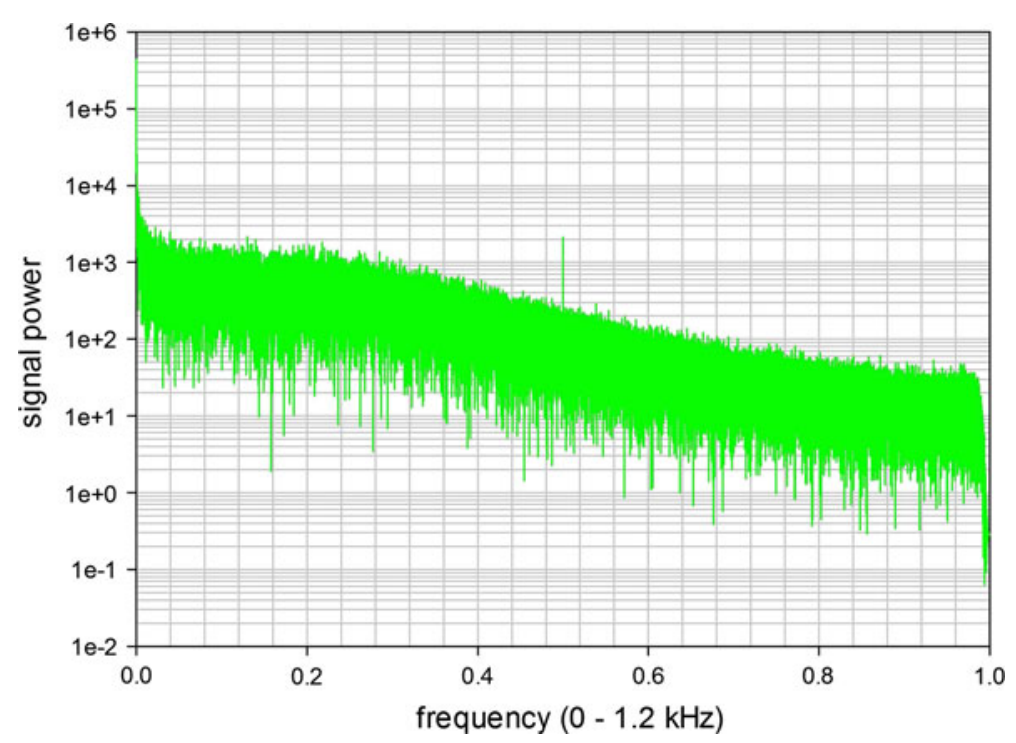

Fig. 8 Power spectrum density of the force signals measured with load cell Nr. 1 of experiment Nr. 1

We then low-pass filtered dataset $A$, considering $f_{\max }$, to obtain signals, measured within a frequency range between 0 and $26 \mathrm{~Hz}$. We denoted this dataset for further analyses as dataset $C$. Figure 7 shows forces over time, based on dataset $C$ of load cell 1 and experiment 1. A visual comparison between the original data (dataset $A$ ) and the low-pass filtered data (dataset $C$ ) hypothesizes that the integral of the impact signals over time are not significantly modified. This assumption is somehow also confirmed by the power spectrum density (PSD) of the force signals based on dataset $A$. On average, the PSD for all experiments and load cells show higher power values of the force signals in lower frequency ranges. An example of a power spectrum density plot of load cell 1 and experiment 1 is given in figure 8 .

\subsection{Peak Flow Heights and Maximum Velocities}

The flow heights for each experiment were scanned with ultrasonic devices at three different locations along the flume (US1, US2 and US3). The ultrasonic device US1 is mounted near the start section, whereas the flow height measurements of US2 and US3 are located near the end of the flume, with US3 being closest to the force plate (Fig. 2). The peak flow height of the experiment was, therefore, detected by the ultrasonic device US3 at the moment when the debris-flow front passes this device. As an example, Fig. 9 shows the measured flow heights over time for the viscous experiment Nr. 1. The red arrow indicates the time point for which the maximum flow height of the experiment $\mathrm{Nr}$. 1 was defined. Here, flow height values after this point of time, exceeding the estimating peak flow height, may originate from the deflection of the force plate and were therefore not used for further analyses. The maximum velocity of the mass was estimated, based on the time when the debris-flow front of the experiment passed the ultrasonic devices.

The estimated peak flow heights as well as the maximum flow velocities of all experiments are listed in Table 3 . 


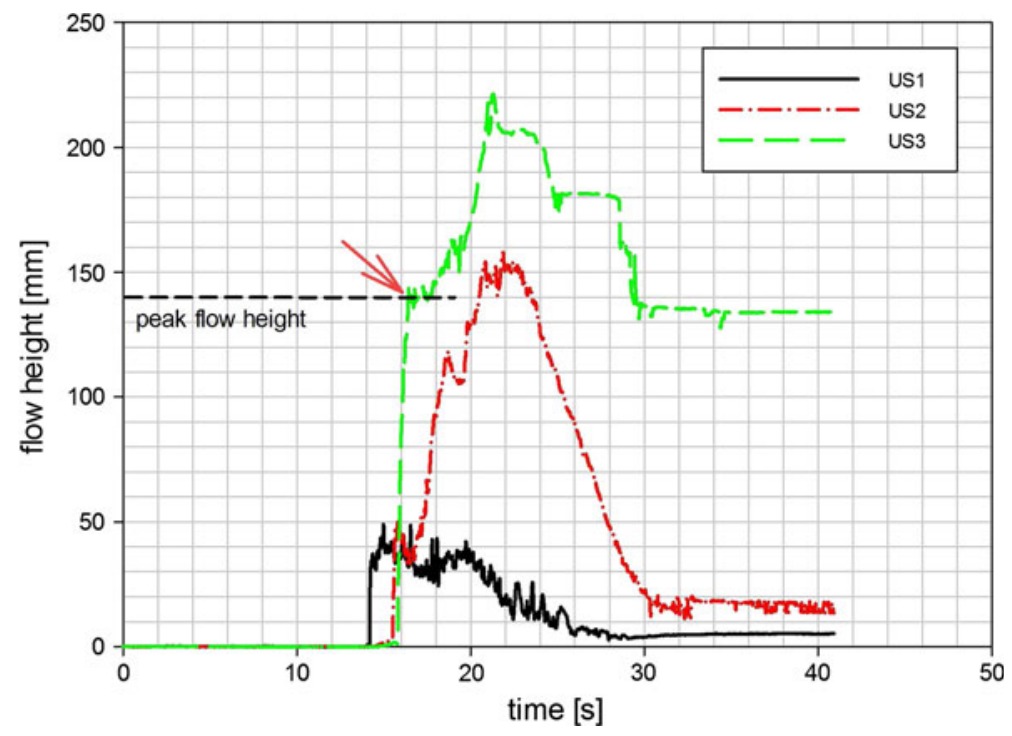

Fig. 9 Measured flow heights over time of the ultrasonic devices US1, US2 and US3 for the experiment Nr. 1. The red arrow indicates the point in time for which the peak flow height was estimated

\section{Results}

Based on the datasets $B$ and $C$, we estimated the maximum forces over time for each load cell and experiment. The entire dataset $A$ was not considered since the effective impact signals might be biased due to random effects in higher frequency ranges. The maximum forces over time are denoted with $F_{n}^{m}$, whereas $n$ defines the number of the load cells ( $n=1-24)$, and $m$ refers to the different datasets $(m=B$ or $C$ ). The value of the highest maximum force $F_{n}^{m}$ for each dataset is then defined as $F_{\max }^{m}$ :

$$
F_{\max }^{m}=\max \left(F_{1}^{m}, F_{2}^{m}, \ldots, F_{24}^{m}\right)
$$

\subsection{Peak Pressure Values}

The peak pressure value for each experiment and dataset $\left(p_{\text {peak }}^{m}\right)$ is based on $F_{\text {max }}^{m}$, related to the constant area of one single load cell:

$$
p_{\text {peak }}^{m}=\frac{F_{\text {max }}^{m}}{0.0016 m^{2}}
$$

Peak pressure values $p_{\text {peak }}^{m^{*}}$ upscaled to prototype conditions (indicated with $*$ ) for all experiments and datasets are listed in Table 4. Further, the approximated time differences between the moment when the debris-flow front reached the force plate and the moment when the peak pressure values were observed are shown.

\subsection{Pressure Coefficients of Hydraulic Impact Models}

The back calculated static pressure factors $k_{n}^{m}$ (cp. Eq. 1), and dynamic pressure factors $a_{\text {calc }}^{m}$ (cf. Eq. 2) for all experiments, respectively, the datasets $B$ and $C$, are based on 
Table 4 Maximum peak prototype pressure values of all experiments and the datasets $B$ and $C$

\begin{tabular}{llccc}
\hline Nr. & Bulk mixture & $p_{\text {peak }}^{B^{* *}}\left[\mathrm{kN} / \mathrm{m}^{2}\right]$ & $p_{\text {peak }}^{C^{*}}\left[\mathrm{kN} / \mathrm{m}^{2}\right]$ & $\Delta t[\mathrm{~s}]$ \\
\hline 1 & Viscous & 324.64 & 339.33 & 5.53 \\
2 & Viscous & 166.76 & 207.16 & 5.62 \\
3 & Viscous & 320.19 & 359.97 & 4.89 \\
4 & Viscous & 194.32 & 258.51 & 0.58 \\
5 & Granular & 284.57 & 398.82 & 0.56 \\
6 & Granular & 289.36 & 313.94 & 0.67 \\
7 & Granular & 392.40 & 411.98 & 0.60 \\
8 & Granular & 145.77 & 181.23 & 0.80 \\
9 & Granular & 133.80 & 155.74 & 1.01 \\
10 & Granular & 161.73 & 192.95 & 0.91 \\
11 & Granular & 253.46 & 629.43 & 0.38 \\
12 & Granular & 280.20 & 650.56 & 0.31 \\
13 & Granular & 369.05 & 684.29 & 0.58 \\
14 & Granular & 428.47 & 568.06 & 1.27 \\
15 & Granular & 337.63 & 740.12 & 0.26 \\
16 & Granular & 386.28 & 1244.01 & 0.29 \\
& Mean value & 279.29 & 458.51 & 1.52 \\
& Standard deviation & 94.93 & 284.98 & 1.93 \\
\hline
\end{tabular}

The approximate time difference between the moment when the debris-flow front reached the force plate and the moment when the maximum pressure values are observed is defined by $\Delta t$

$$
k_{\mathrm{calc}}^{m}=\frac{p_{\mathrm{peak}}^{m}}{\rho_{d f} g h_{\mathrm{peak}}}
$$

and

$$
a_{\mathrm{calc}}^{m}=\frac{p_{\mathrm{peak}}^{m}}{\rho_{d f} \nu^{2}}
$$

On average, we measured peak pressures, exceeding the hydrostatic pressure by a factor of approximately seven (averaged dataset $B$ ). The measured peak pressure values based on dataset $C$ exceeds the hydrostatic pressure by a factor of twelve. Compared to the different $k$ factors for selected impact models (Table 1), the back calculated coefficients $\left(k_{\text {calc }}\right)$ for the averaged dataset $B$ are within an order of magnitude of those proposed by Hübl et al. (2009) and are similar to the laboratory results of Armanini (1997).

The back calculated coefficients of the dynamic approach, based on dataset $B$ also fit to the range of proposed data in literature. Higher peak pressure values of dataset $C$ also yield a higher related dynamic coefficient. Back calculated dimensionless coefficients for all experiments and datasets are listed in Table 5. Figure 10a shows the correlations of back calculated hydrostatic coefficients with Froude numbers for all experiments, separated for the datasets $B$ and $C$.

The correlations of back calculated hydrodynamic coefficients with Froude numbers are given in Figure 10b. Also shown are the correlations of the modified impact model (Eq. 3) of Hübl and Holzinger (2003) as well as the field based dynamic impact model as proposed 
Table 5 Back calculated dimensionless coefficients $k_{\text {calc }}$ and $a_{\text {calc, }}$, for the dataset $B$ and $C$, as well as Froude numbers for each experiment

\begin{tabular}{llrcccc}
\hline Nr. & Bulk mixture & $k_{\text {calc }}^{B}[-]$ & $k_{\text {calc }}^{C}[-]$ & $a_{\text {calc }}^{B}[-]$ & $a_{\text {calc }}^{C}[-]$ & $F_{r}[-]$ \\
\hline 1 & Viscous & 5.91 & 6.18 & 4.42 & 4.62 & 1.16 \\
2 & Viscous & 5.31 & 6.60 & 4.81 & 5.98 & 1.05 \\
3 & Viscous & 6.80 & 7.64 & 5.96 & 6.70 & 1.07 \\
4 & Viscous & 7.07 & 9.41 & 2.98 & 3.96 & 1.54 \\
5 & Granular & 4.53 & 6.35 & 12.09 & 16.95 & 0.61 \\
6 & Granular & 4.76 & 5.16 & 8.15 & 8.84 & 0.76 \\
7 & Granular & 6.90 & 7.24 & 10.66 & 11.20 & 0.80 \\
8 & Granular & 2.65 & 3.30 & 3.42 & 4.25 & 0.88 \\
9 & Granular & 3.10 & 3.61 & 6.36 & 7.40 & 0.70 \\
10 & Granular & 3.17 & 3.78 & 10.05 & 11.98 & 0.56 \\
11 & Granular & 5.17 & 12.83 & 2.94 & 7.29 & 1.33 \\
12 & Granular & 10.20 & 23.68 & 1.52 & 3.53 & 2.59 \\
13 & Granular & 15.67 & 29.06 & 1.53 & 2.84 & 3.20 \\
14 & Granular & 11.49 & 15.24 & 3.11 & 4.12 & 1.92 \\
15 & Granular & 10.76 & 23.58 & 1.86 & 4.07 & 2.41 \\
16 & Granular & 9.38 & 30.19 & 2.98 & 9.60 & 1.77 \\
& Mean value & 7.05 & 12.12 & 5.18 & 7.08 & 1.40 \\
& Standard deviation & 3.58 & 9.34 & 3.40 & 3.84 & 0.79 \\
\hline
\end{tabular}

by Bugnion et al. (2011). All dynamic coefficients are assumed to be constant for the plotted range of Froude regimes.

\section{Discussion}

Our experiments show that signal processing of the raw data influences the coefficients of resulting impact models, significantly. Dataset $A$ carried most of the information on impact data, but uncertainties exist due to several effects. Beside the resonance frequency of the flume apparatus, these effects might also be due to single hard impacts. Bugnion et al. (2011) suggest that the presence of a solid phase can increase local impact pressure due to hard contact and material locking - a phenomenon that is observed in dry granular flows (Levy and Sayed 2008) and at the head of some debris flows. In fact, observations of debris-flow events confirm the transportation of large boulders at the front (Takahashi 1991; Berti et al. 1999; Hürlimann et al. 2003). These hard contacts, often caused by single blocks, are not yet fully analysed, but might have a higher impact on barriers compared to the estimations of maximum pressure values due to hydraulic based models.

With every experiment, we also could observe peak pressure values at the flow front, up to 10 times higher compared to the mean peak pressure values of the complete debris-flow wave propagation (cf. Fig. 6). Video analysis shows that the reason for this effect is caused by the impact of single boulders, occasionally dissociated from the flow front. These maximum pressure values can only be detected by the unfiltered impact signals (dataset $A$ ), due to their very short lifetime $(\approx 0.05 \mathrm{~s})$. The high peak pressure values over this very short time result in a low momentum transfer to the force plate. For this reason, we assume that the maximum loading, based on our unfiltered maximum impact signals, might not 

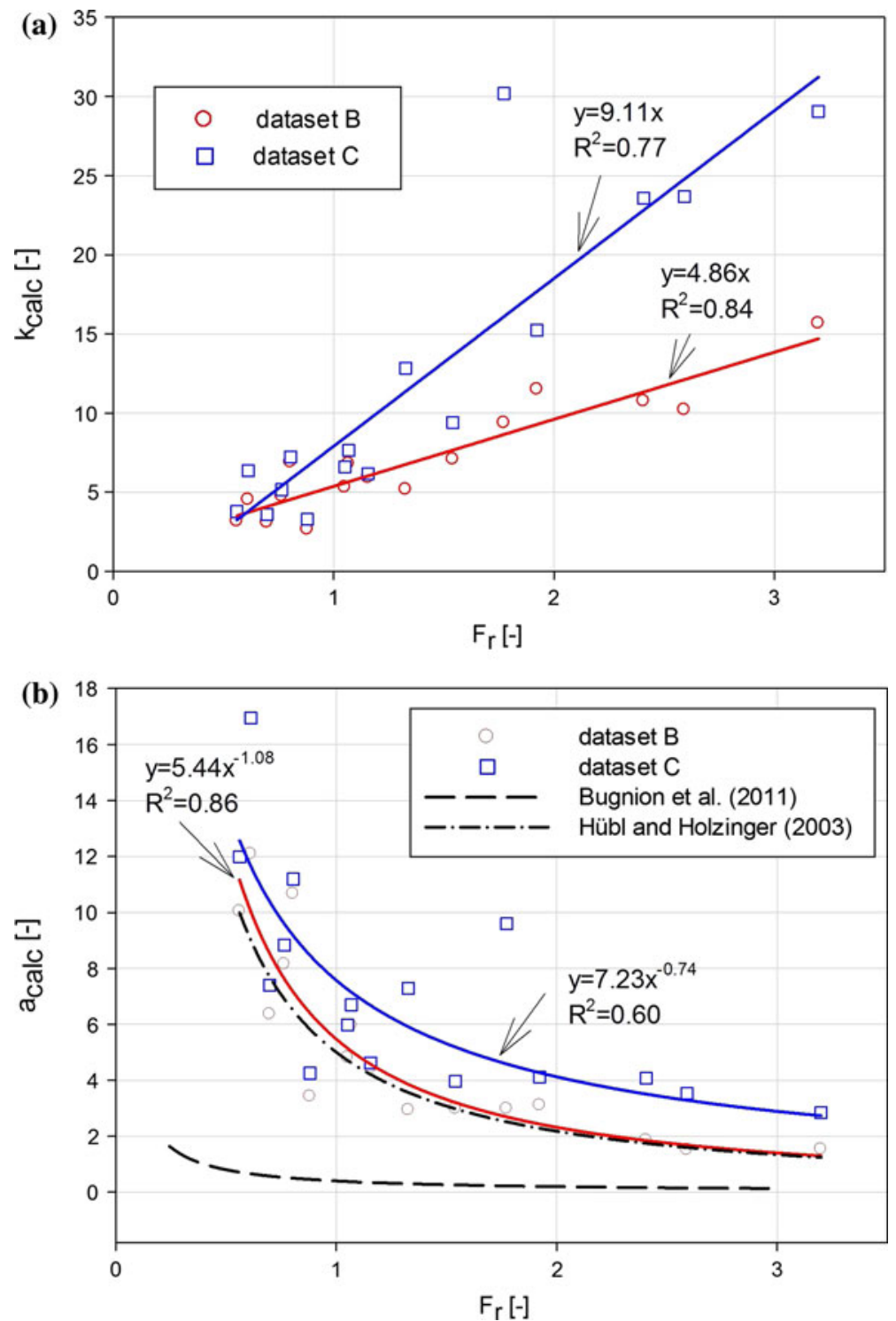

Fig. 10 a Correlation of back calculated hydrostatic coefficients and Froude numbers for all experiments. b Correlation of back calculated hydrodynamic coefficients and Froude numbers for all experiments. The dashed trend lines refer to the impact models of Hübl and Holzinger (2003) and Bugnion et al. (2011)

lead to significant damage. However, little is known about these individuals impacts causing maximum stresses in a very short time and future research is needed to discover their effects on potential mitigation structures.

The filtered impact signals (dataset $B$ ) refer to median impact forces acting over a time period of $0.25 \mathrm{~s}$. For prototype conditions, this corresponds roughly to a minimum impact duration of $1 \mathrm{~s}$, which might be a realistic impact scenario. Further, dataset $B$ reduces 
random effects and the back calculated impact coefficients are within the range of the proposed coefficients proposed in the literature.

The entire dataset $C$ of the lowpass filtered impact signals reduced the observed peak pressure values of dataset $A$, but showed the same integral of impact signals over time as dataset $B$. No outstanding peak pressure values can be detected, but still for dataset $C$ the minimum approximated impact duration of one single signal amounts to $0.20 \mathrm{~s}$ and shows on average $50 \%$ higher peak pressure values, compared to the results of the averaged datasets $B$. However, peak pressure values of dataset $C$ are within the range of uncertainty of dataset $B$ for all experiments.

Nevertheless, impact models based on a reduced dataset might miss information of peak pressure values based on single hard impacts, acting over a longer time period. Here, more research is needed to define a critical duration of impacts or modified design criteria based on impact duration.

A clear distinction between viscous and granular setups can be observed, regarding the time difference $(\Delta t)$ between the moment when the debris-flow front reached the force plate and the moment when the maximum pressure values were measured. Here, maximum pressure values for the granular setups were constantly measured close to the point in time when the debris-flow front reached the force plate. For the viscous setups, we observed a significant time lag between the first impact and the maximum measured impact. This retarded reaction might be due to an increase in the pore water pressure from the debrisflow front to its tail caused by the fine material within the bulk mixture.

The Austrian code series, which is currently under development, considers the hydrostatic model proposed by Armanini (1997) and the modified hydrodynamic model of Hübl and Holzinger (2003). In principle, our data show that the dynamic impact coefficients linearly correlate to the inverse of the Froude numbers (Fig. 10b). The peak pressures can therefore also be estimated by means of:

$$
p_{\text {peak }}=\epsilon \rho_{d f} v(g h)^{1 / 2}
$$

with $\epsilon$ reflecting the dimensionless impact coefficients ( $k$ and $a$ ) at Froude number $F_{r}=1$.

Since we assume Froude scaling ( $\epsilon$ is constant for the applied Froude range) we substitute Eq. 14 with

$$
(g h)^{1 / 2} \propto v
$$

resulting in

$$
p_{\text {peak }}=\epsilon \rho_{d f} v^{2}
$$

Figure $10 \mathrm{~b}$ as well as Eqs. (14-16) show that the modified impact model (Eq. 3), as proposed by Hübl and Holzinger (2003), is very close to the general form of the dynamic impact model (Eq. 2), which is physically approved and confirmed by several experiments. However, considering the hydrodynamic model in detail $(\epsilon=a)$, our data show higher back calculated dynamic impact coefficients with increasing Froude numbers (Table 5). The divergence between the correlation proposed by Bugnion et al. (2011) and the correlation found for this study and for Hübl and Holzinger (2003) (Fig. 10b) might be explained by the different examined process types (hill slope debris flows vs. debris flows). Further, data of this study as well as of Hübl and Holzinger (2003) are based on a small scale modelling approach, whereas the real-scale experiments by Bugnion et al. (2011) showed higher turbulences, respectively, higher turbulence and higher Froude numbers. It 
seems that the variable impact coefficients due to the complex rheological characteristics of the flowing mass is to some extent reflected by the Froude regime. These aspects need to be further evaluated with laboratory and field data.

\section{Conclusion}

The small scale modelling approach to measure horizontal debris-flow forces is confirmed by existing impact models, although our study shows that the kind of signal processing of the raw impact data has a big influence. The correlation between the Froude numbers and the dimensionless coefficients of the hydrostatic and hydrodynamic models underline the approach to fulfil kinematic similarity when analysing debris-flow impact forces based on a physical model in the laboratory. We further conclude that the general form of the dynamical impact model shows more plausible results, compared to the general form of the hydrostatic model.

Typically, load cases for dimensioning debris-flow barriers account either for a single block impact or for hydrostatic or hydrodynamic impacts, which act over the total flow height. Our small scale experiments gave evidence to debate a combination or enlargement of these two load cases, considering individual punctual impacts, causing maximum stresses at the moment when the flow front hits the structure.

Acknowledgments The study is part of the research project "Historical arch bridges under horizontal debris flow impacts" funded by the Austrian Science Fund (FWF), project nr.: P21653. The authors thank Prof. Dr. Ottner from the Institute of Applied Geology (BOKU) for analysing the clay material, and Dr. Sinn from the Institute of Physics and Material Sciences (BOKU) for providing us the technology to calibrate the load cells used in this study. The authors also thank Fabian Steinkellner for his fundamental work on the design of the force plate panel.

Open Access This article is distributed under the terms of the Creative Commons Attribution License which permits any use, distribution, and reproduction in any medium, provided the original author(s) and the source are credited.

\section{References}

Arattano M, Franzi L (2003) On the evaluation of debris flows dynamics by means of mathematical models. Nat Hazards Earth Syst Sci 3(6):539-544. doi:10.5194/nhess-3-539-2003

Armanini A (1997) On the dynamic impact of debris flows. In: Armanini A, Masanori M (eds) Recent developments on debris flows, lecture notes in earth sciences, Springer, Berlin, pp 208-226

Armanini A, Scotton P (1992) Experimental analysis on the dynamic impact of a debris flow on structures. In: Internationales symposion interpraevent 1992, vol 6, Bern, pp 107-116

Berti M, Genevois R, Simoni A, Tecca PR (1999) Field observations of a debris flow event in the dolomites. Geomorphology 29:265-274. doi:10.1016/S0169-555X(99)00018-5

Bugnion L, McArdell B, Bartelt P, Wendeler C (2011) Measurements of hillslope debris flow impact pressure on obstacles. Landslides, pp 1-9. doi:10.1007/s10346-011-0294-4

Cui P, Chen X, Waqng Y, Hu K, Li Y (2005) Jiangia ravine debris flows in southwestern china. In: Jakob M, Hungr O (eds) Debris-flow hazards and related phenomena, Springer, Berlin, pp 565-594

D’Agostino V, Cesca M, Marchi L (2010) Field and laboratory investigations of runout distances of debris flows in the dolomites (eastern italian alps). Geomorphology 115(3-4):294-304. doi:10.1016/ j.geomorph.2009.06.032

Davies T (1994) Dynamically similar small-scale debris flow models. In: University of Trento I (ed) International workshop on floods and inundations related to large earth movements, IAHS Publication, p 11

DeNatale J, Iverson R, Major J, LaHusen R, Fiegel G, Duffy J (1999) Experimental testing of flexible barriers for containment of debris flows. US Geological Survey Open-File Report 205:38 
Egli T (2005) Wegleitung, Objektschutz gegen gravitative Naturgefahren. Vereinigung Kantonaler Feuerversicherungen (VKF)

Hu K, Wei F, Li Y (2011) Real-time measurement and preliminary analysis of debris-flow impact force at jiangjia ravine, china. Earth Surf Process Landf 36:1268-1278 doi:10.1002/esp.2155

Hübl J, Holzinger G (2003) Entwicklung von Grundlagen zur Dimensionierung kronenoffener Bauwerke für die Geschiebebewirtschaftung in Wildbächen: Kleinmassstäbliche Modellversuche zur Wirkung von Murbrechern. WLS Report 50 Band 3, Institut of Mountain Risk Engineering

Hübl J, Suda J, Proske D, Kaitna R, Scheidl C (2009) Debris flow impact estimation. In: Popovska C, Jovanovski $\mathrm{M}$ (eds) Eleventh international symposium on water management and hydraulic Engineering, vol 1, pp 137-148

Hürlimann M, Rickenmann D, Graph C (2003) Field and monitoring data of debris-flow events in the swiss alps. Can Geotech J 40:161-175

Ishikawa N, Inoue R, Hayashi K, Hasegawa Y, Mizuyama T (2008) Experimental approach on measurement of impulsive fluid force using debris flow model. In: Conference proceedings interpraevent 08

Iverson RM (1997) The physics of debris flows. Rev Geophys 35(3):245-296

Iverson RM, Denlinger RP (2001) Flow of variably fluidized granular masses across three-dimensional terrain. J Geophys Res 106:537-552. doi:1.1029/2000JB900329

Iverson RM, Reid ME, Logan M, LaHusen RG, Godt JW, Griswold JP (2011) Positive feedback and momentum growth during debris-flow entrainment of wet bed sediment. Nat Geosci 4(2):116-121. doi: $10.1038 /$ ngeo 1040

Kherkheulidze I (1969) Estimation of basic characteristics of mudflows ('sel'). In: Floods and their computation, International Association of Scientific Hydrology Publication, Leningrad, vol 2, 940-948

König U (2006) Real scale debris flow tests in the Schesatobel-valley. Master's thesis, University of Natural Resources and Life Sciences, Vienna, Austria

Levy A, Sayed M (2008) Numerical simulations of the flow of dilute granular materials around obstacles. Powder Technol 181(2):137-148. doi:10.1016/j.powtec.2006.12.005

Lichtenhahn C (1973) Die Berechnung von Sperren in Beton und Eisenbeton. In: Kolloquium über Wildbachsperren, Mitteilungen der Forstlichen Bundesanstalt Wien, vol 102, pp 91-127

Monney J, Herzog B, Wenger M, Wendeler C, Roth A (2007) Einsatz von multiplen Stahlnetzbarrieren als Murgangruckhalt. Wasser Energie Luft 3:255-259

S, Suwa H, Okunishi K, Nakano K, K Y (1977) General observations of debris flow (iii), 1976 yakedake kamikamihorizawa. In: Annual report of the Disaster Prevention Research Institute at Kyoto University, vol 20B, pp 237-263

Proske D, Kaitna R, Suda J, Hübl J (2008) Abschätzung einer Anprallkraft für murenexponierte Massivbauwerke. Bautechnik 85(12):803-811. doi:10.1002/bate.200810059

Scotton P, Deganutti A (1997) Phreatic line and dynmaic impact in laboratory debris flow experiments. In: Chen C (ed) Proceedings of the 1st. international conference on debris-flow hazards mitigation: mechanics, prediction and assessment, American Society of Civil Engineers, New York, pp 777 - 786

Shieh CL, Ting CH, Pan HW (2008) Impulsive force of debris flow on a curved dam. Int J Sediment Res 23:149-158. doi:10.1016/S1001-6279(08)60014-1

Takahashi T (1991) Debris flow. IAHR Monograph Series, A.A.Balkema / Rotterdam / Brookfield

Tecca PR, Galgaro A, Genevois R, Deganutti A (2003) Development of a remotely controlled debris flow monitoring system in the dolomites (acquabona, italy). Hydrol Process 17:1771-1784

Thornton C (1997) Coefficient of restitution for collinear collisions of elastic-perfectly plastic spheres. J Appl Mech 64(2):383-386. doi:10.1115/1.2787319

Tiberghien D, Laigle D, Naaim M, Thibert E, Ousset F (2007) Experimental investigation of inter-action between mudflow and obstacle. In: Chen C, Major J (eds) Debris-flow hazards mitigation: mechanics, prediction and assessment, Millpress, Rotterdam

VanDine DF (1996) Debris flow control structures for forest engineering. Working paper, Ministry of Forest Research Program, Victoria, British Columbia

VAW (1992) Murgänge 1987, Dokumentation und Analyse, Bericht Nr.: 97.6 der Versuchsanstalt für Wasserbau, Hydrologie und Glaziologie, ETH Zürich

Walton O, Braun RL (1986) Viscosity, granular-temperature, and stress calculations for shearing assemblies of inelastic frictional disks. J Rheol 30:949-980

Watanabe M, Ike (1981) Investigation and analysis of volcanic mud flows on mount sakurajima. japan. In: Erosion sediment transport measurement, International Association on Hydrology, Florence, Science Publication, vol 133, 245-256

Wendeler C (2008) Murgangsrückhalt in wildbächen. grundlage zur planung und berechnung von flexiblen barrieren. PhD thesis, Swiss Federal Institute of Technology Zurich, Zürich. doi:10.3929/ ethz-a-005699588 
Wendeler C, Volkwein A, Denk M, Roth A, Wartmann S (2007) Field measurements used for numerical modelling of flexible debris flow barriers. In: Chen C, Major J (eds) Debris-flow hazards mitigation mechanics, prediction and assessment, Millpress, Rotterdam

Zhang S (1993) A comprehensive approach to the observation and prevention of debris flows in china. Nat Hazards 7:1-23. doi:10.1007/BF00595676 